\title{
BA and Sucrose Increase Vase Life of Cut Eustoma Flowers
}

\author{
Kuang-Liang Huang \\ Department of Horticulture, National Chiayi University, Chia-Yi City, \\ Taiwan, $R O C$ \\ Wen-Shaw Chen ${ }^{1}$ \\ Department of Biological Sciences, National Sun Yat-Sen University, Kaoshiung \\ City, Taiwan, ROC \\ Additional index words. Eustoma grandiflorum, ethylene, respiration
}

\begin{abstract}
An experiment was conducted to measure the effects of pulse treatments of BA, sucrose, and BA before, after, or with sucrose, on the vase life of cut Eustoma flowers. A BA pulse at $50 \mathrm{mg} \cdot \mathrm{L}^{-1}$ before $4 \%$ sucrose promoted the longevity of cut Eustoma flowers better than other treatments. Simultaneously, sucrose, glucose, and mannose concentrations in flowers during vase periods were maintained at higher levels in double pulse treatments than in the single pulses. Ethylene production in flowers 2 days after vase treatment was highest in the BA-treated flowers; intermediate in flowers pulsed with BA before, after, or with sucrose; and lowest in sucrose-treated flowers. Although a BA pulse increased ethylene production over that of controls, it inhibited senescence in cut Eustoma flowers. Respiration in flowers pulse-treated with sucrose or with BA before, after, or with sucrose, was significantly higher than that in controls. Results suggest that the vase life of cut Eustoma flowers is improved by either BA or sucrose in vase solution and especially when BA was pulsed before the sucrose pulse. Chemical name used: $\mathbf{N}^{6}$-benzyladenine (BA).
\end{abstract}

Exogenous application of cytokinin to detached leaves delays the onset of senescence (Binns, 1994; Letham and Palni, 1983), and promotes the transport of solutes from older to younger parts of a plant (Letham and Palni, 1983). Kinetin application at low concentrations delayed senescence in tobacco leaf discs, but at the same time stimulated ethylene production in them (Fuchs and Lieberman, 1978; Lau and Yang, 1973). Sugar promotes flower bud opening in many cut flowers (Ichimura and Korenaga, 1998; Kuiper et al., 1995; Mayak et al., 1973). Ichimura and Hiraya (1999) reported that a sucrose pulse treatment extended the vase life and inhibited ethylene production in cut sweet pea florets regardless of their stage of development. In addition, 8-hydroxyquinoline sulfate (HQS) inhibits the occurrence of bent-neck in cut rose flowers (Burdett, 1970) and improves water relations by inhibiting both vascular blockage and transpiration (Halevy and Mayak, 1981). Climacteric ethylene production in cut sweet pea flowers was unaffected by HQS (Ichimura et al., 1998). Since HQS is a germicide, its effectiveness could be partially due to inhibition of bacterial proliferation (Marousky, 1969).

Our studies were undertaken to investigate the effects of pulse treatments of BA, sucrose, BA before or after sucrose, and BA with sucrose on vase life, changes in sugars and ethylene and respiration in cut Eustoma flowers during vase treatments.

Received for publication 2 Jan. 2001. Accepted for publication 5 July 2001.

${ }^{1}$ To whom reprint requests should be addressed.

\section{Materials and Methods}

Eustoma grandiflorum Shinn. cv. Heide flowers with stems initially $\approx 40 \mathrm{~cm}$ long were used. Flower stems were packed in corrugated cardboard boxes and transported to the National Chiayi Univ. $\approx 2 \mathrm{~h}$ after harvesting in Chia-Yi County, Taiwan. Cut flowers were immediately recut in deionized water, and placed in 1000-mL flasks containing $800 \mathrm{~mL}$ of vase solution. The cut flowers were kept at $25^{\circ} \mathrm{C}, 15 \mu \mathrm{mol} \cdot \mathrm{m}^{-2} \cdot \mathrm{s}^{-1}$ photosynthetic photon flux using cool-white florescent lamps (Philips, Taoyung County, Taiwan) with a 14-h photoperiod. The cut stems were treated with water controls, BA at $50 \mathrm{mg} \cdot \mathrm{L}^{-1}$, $4 \%$ sucrose, BA at $50 \mathrm{mg} \cdot \mathrm{L}^{-1}$ before or after $4 \%$ sucrose, and $\mathrm{BA}$ at $50 \mathrm{mg} \cdot \mathrm{L}^{-1}+4 \%$ sucrose. All solutions contained $200 \mathrm{mg} \cdot \mathrm{L}^{-1}$ of HQS. Either the sucrose pulses, BA pulses, or both, were given once for $24 \mathrm{~h}$ each. Vase life was recorded as the number of days from the end of the pulse treatments until the day when the last flower senesced. A randomized complete-block design was used with four cut stems per flask, and four replicate flasks per treatment. data were subjected to analysis of variance (ANOVA) (SAS Institute, 1989), and the means were separated using Duncan's multiple range test.

Determination of sugar concentrations in flowers. Sugar analysis (sucrose, glucose, mannose, and ribose) was done as described by Chen et al. (1994). Open flowers were ground in a laboratory blender with $95 \%$ ethanol, and filtered through Whatman No. 1 papers. The residues were re-extracted three times with the same solvent. The combined solvent was centrifuged at $10,000 \mathrm{~g}$ for 15 min. The resulting supernatant was evaporated at $35^{\circ} \mathrm{C}$ to dryness under vacuum. The dried sample was dissolved in $1 \mathrm{~mL}$ distilled water, and filtered through a $0.45-\mu \mathrm{m}$ millipore filter. The filtrate was used for HPLC (Hitachi-L-7100, Tokyo) analysis. Sugars were separated with a Sugar Pak 1 column $(300 \times 6.5 \mathrm{~mm}$ i.d., Waters Associates, Milford, Mass.) at $90{ }^{\circ} \mathrm{C}$ using water $(0.5 \mathrm{~mL} / \mathrm{min})$ as eluant. The sugars were identified by their retention times vs. pure standards and quantified by integrating peak areas. Three replicate flowers were used in each sampling date. Means of sugar contents were compared using ANOVA.

Measurement of ethylene and $\mathrm{CO}_{2}$ production in flowers. One flower was sealed in a 125-mL Erlenmeyer flask and kept at $25^{\circ} \mathrm{C}$. After $2 \mathrm{~h}, 1-\mathrm{mL}$ gas samples were withdrawn with a hypodermic syringe for ethylene determination. Ethylene content in 1-mL gas samples was measured using a gas chromatograph equipped with an activated alumina column fitted with a flame ionization detector. Carbon dioxide concentration was determined using an infrared gas analyzer. Ethylene and $\mathrm{CO}_{2}$ production rates of three replicate flowers were calculated and were compared using ANOVA.

\section{Results and Discussion}

Both BA and sucrose pulse treatments prolonged vase life, inhibiting Eustoma senescence (Table 1). BA also stimulated ethylene production, whereas sucrose suppressed it (Fig. 1). When cut Eustoma flowers were placed in a sucrose solution, ethylene production in the initial stages of vase treatment was significantly lower than that of flowers in BA or control solutions (Fig. 1). Therefore, the improved vase life of BAtreated flowers cannot be attributed to suppression of ethylene production. Cytokinins may have a complex role in delaying senescence, probably acting on different systems. When cut Eustoma flowers were treated with BA pulses before or after sucrose, or in BA + sucrose, the effectiveness on longevity was: $\mathrm{BA}$ before sucrose $>\mathrm{BA}+$ sucrose $=\mathrm{BA}$ after sucrose (Table 1). Furthermore, flowers treated with both BA and sucrose (double pulse) were better in maintaining longevity than those treated with BA or sucrose. How-

Table 1. Effects of a BA pulse at $50 \mathrm{mg} \cdot \mathrm{L}^{-1}, 4 \%$ sucrose, or both on longevity of Eustoma flowers. BA and/or sucrose were pulsed for $24 \mathrm{~h}$, respectively, and then transferred to water. All solutions contained HQS at $200 \mathrm{mg} \cdot \mathrm{L}^{-1}$. Data are means of 16 replications $\pm \mathrm{SD}$.

\begin{tabular}{lc}
\hline Treatment & $\begin{array}{c}\text { Flower } \\
\text { longevity (days) }\end{array}$ \\
\hline Control & $7.1 \pm 0.2 \mathrm{~d}^{\mathrm{z}}$ \\
$\mathrm{BA} \rightarrow$ water & $10.2 \pm 0.4 \mathrm{c}$ \\
$\mathrm{Sucrose} \rightarrow$ water & $10.5 \pm 0.3 \mathrm{c}$ \\
$\mathrm{BA} \rightarrow$ sucrose $\rightarrow$ water & $15.8 \pm 0.4 \mathrm{a}$ \\
$\mathrm{Sucrose} \rightarrow \mathrm{BA} \rightarrow$ water & $12.2 \pm 0.4 \mathrm{~b}$ \\
$\mathrm{BA}+$ sucrose $\rightarrow$ water & $12.5 \pm 0.5 \mathrm{~b}$ \\
\hline
\end{tabular}

${ }^{\text {z} M e a n ~ s e p a r a t i o n ~ w i t h i n ~ c o l u m n ~ b y ~ D u n c a n ' s ~}$ multiple range test, $P \leq 0.05$. 
ever, ethylene production was significantly greater in double pulse treatments than in sucrose alone (Fig. 1). Ethylene production in the initial stages following the double pulse treatments was higher in BA before sucrose than in BA after sucrose. However, except for day 2 , no significant difference in ethylene production was found between pulses of BA before sucrose and BA + sucrose (Fig. 1). It seems likely that the high ethylene production in double pulse treatments was due to $\mathrm{BA}$ rather than sucrose. $\mathrm{CO}_{2}$ produc- tion in controls was significantly lower than that in all other treatments (Fig. 2).

In the single pulse study, the concentrations of sucrose, glucose, and mannose were highest in sucrose-treated flowers, intermediate in BAtreated flowers, and lowest in controls (Fig. 3). Mayak and Dilley (1976) reported that kinetin was effective in delaying wilting in carnation flowers. The positive effect of kinetin was increased when sucrose was also included in the vase solution. In the double pulse study, sugar (sucrose, glucose, mannose, and ribose) levels were not significantly different (Fig. 3), suggesting that a pulse of BA either before or after sucrose, or BA + sucrose increased sink strength in flowers and accelerated translocation of sugar from the vase solution to the flower organs. The sugar contents in florets were: BA before sucrose $=\mathrm{BA}+$ sucrose $=\mathrm{BA}$ after sucrose $>$ sucrose $>$ BA $>$ controls (Fig. 3). We suggest that the relatively high levels of flower carbohydrate concentrations coupled with BA effects produced longer vase life in Eustoma. The data are consistent with the finding that sugars

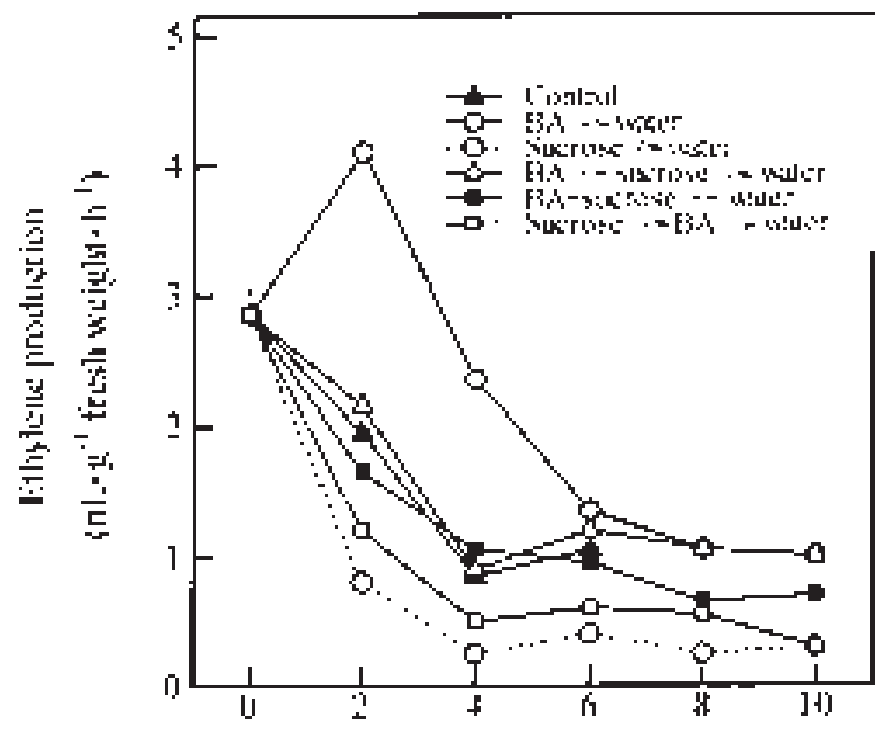

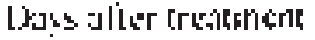

Fig. 1. Effects of pulse treatments of BA at $50 \mathrm{mg} \cdot \mathrm{L}^{-1}, 4 \%$ sucrose, or both, on ethylene production $\left(\mathrm{nL} \cdot \mathrm{g}^{-1}\right.$ fresh weight/h) in Eustoma flowers. All solutions contained HQS. Each value is the mean of three replicate samples. Vertical bars indicate SD when larger than the symbol.

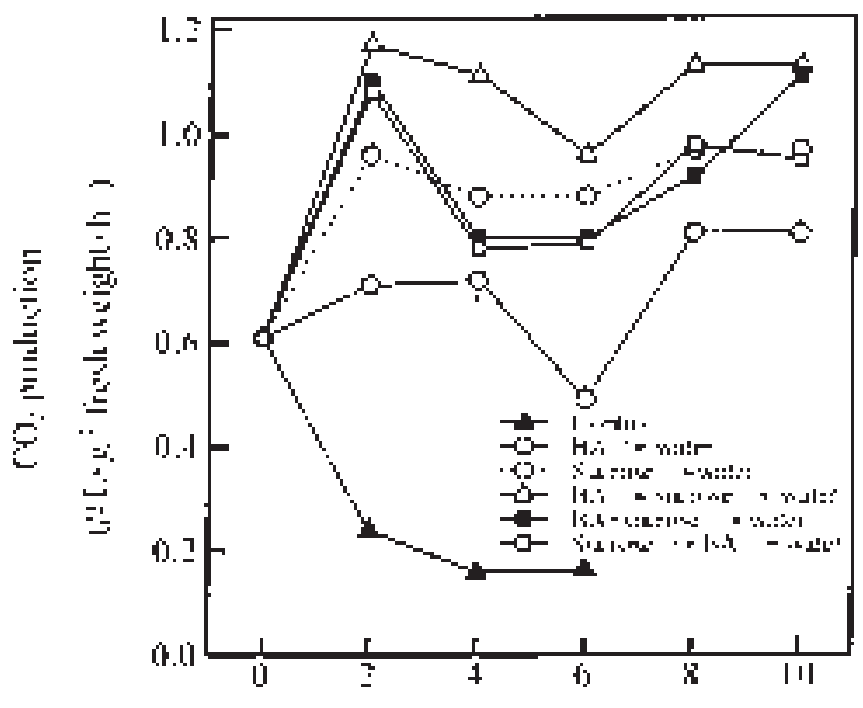

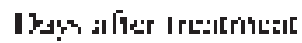

Fig. 2. Effects of pulse treatments of $\mathrm{BA}$ at $\mathrm{mg} \cdot \mathrm{L}^{-1}, 4 \%$ sucrose, or both, on $\mathrm{CO}_{2}$ production $\left(\mathrm{L} \cdot \mathrm{g}^{-1}\right.$ fresh weight/h) in Eustoma flowers. All solutions contained HQS. Each value is the mean of three replicate samples. Vertical bars indicate SD when larger than the symbol.

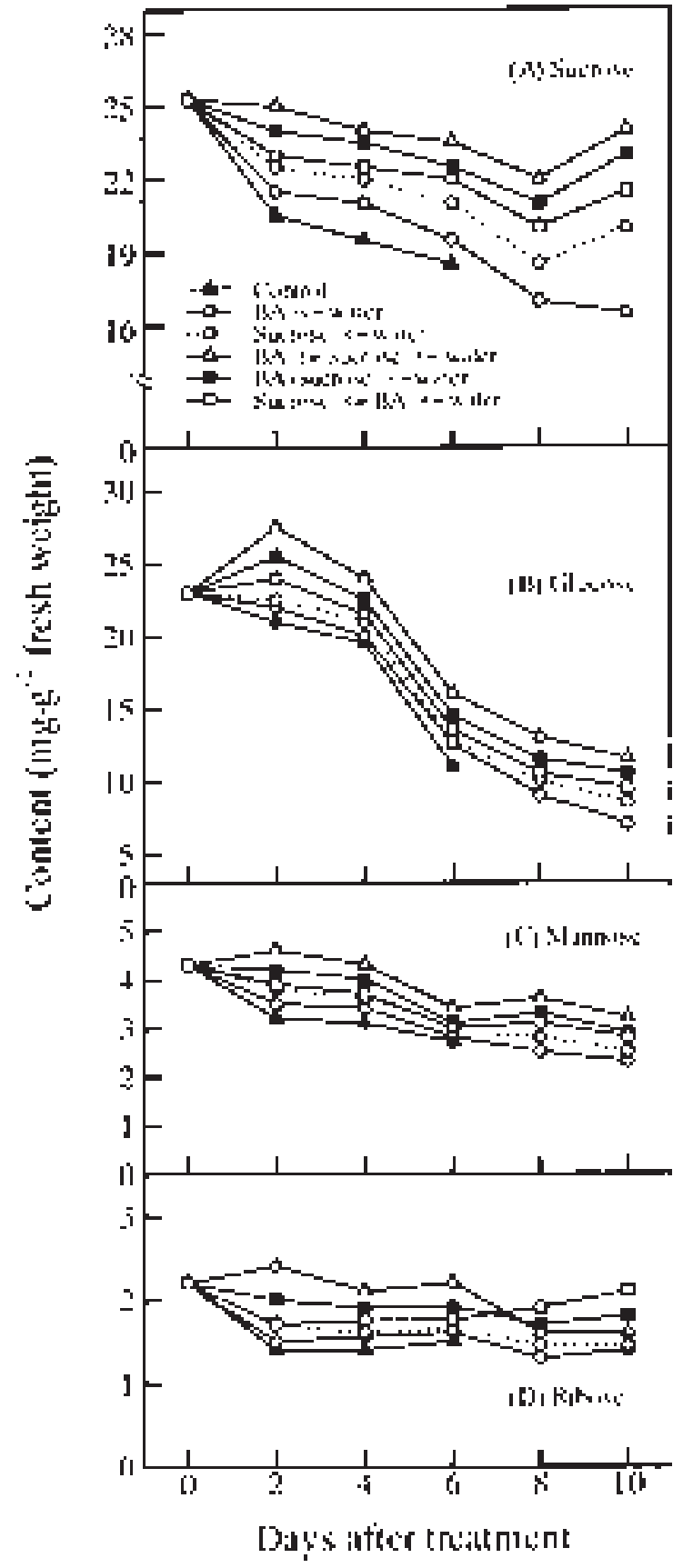

Fig. 3. Effects of pulse treatments of BA at $50 \mathrm{mg} \cdot \mathrm{L}^{-1}, 4 \%$ sucrose, or both, on sugar content (mg. $\mathrm{g}^{-1}$ fresh weight) in Eustoma flowers. All solutions contained HQS. Each value is the mean of three replicate samples. Vertical bars indicate SD when larger than the symbol. 
such as sucrose extend the vase life of cut roses (Halevy and Mayak, 1981). Sucrose and glucose were the main carbohydrates, followed by mannose and ribose in Eustoma flowers (Fig. 3). In the controls, concentrations of sucrose and glucose rapidly decreased during vase life.

In conclusion, the experimental results suggest that the vase life of cut Eustoma flowers is improved by either BA or sucrose in vase solution, and especially when BA is pulsed before the sucrose pulse.

\section{Literature Cited}

Binns, A.N. 1994. Cytokinin accumulation and action: Biochemical, genetic, and molecular approaches. Annu Rev. Plant Physiol. Plant Mol. Biol. 45:173-196.

Burdett, A.N 1970. The cause of bent neck in cut roses. J. Amer. Soc. Hort. Sci. 95:427-431.
Chen, W.S., H.Y. Liu, Z.H. Liu, L. Yang, and W.H. Chen. 1994. Gibberellin and temperature influence carbohydrate content and flowering in Phalaenopsis. Physiol. Plant. 90:391-395.

Fuchs, Y. and M. Lieberman. 1978. Effect of kinetin, IAA and gibberellin on ethylene production and their interaction in growth of seedlings. Plant Physiol. 43:2029-2036.

Halevy, A.H. and S. Mayak. 1981. Senescence and postharvest physiology of cut flowers. Part 2 , Hort. Rev. 3:59-143.

Ichimura, K. and M. Korenaga. 1998. Improvement of vase life and petal color expression in several cultivars of cut Eustoma flowers using sucrose with 8-hydroxyquinoline sulfate. Bul. Natl. Ornam. Plants and Tea, Japan 13:31-39.

Ichimura, K. and T. Hiraya. 1999. Effect of silver thiosulfate complex (STS) in combination with sucrose on the vase life of cut sweet pea flowers. J. Jpn. Soc. Hort. Sci. 68:23-27.

Kuiper, D., S. Ribot, H.S. van Reenen, and N. Marissen. 1995. The effect of sucrose on the flower bud opening of Madelon cut roses.
Scientia Hort. 60:325-336.

Lau, O.L. and S.F.Yang. 1973. Mechanisms of a synergistic effect of kinetin on auxin induced ethylene production: Suppression of auxin conjugation. Plant Physiol. 51:1011-1014.

Letham, D.S. and L.M.S. Palni. 1983. The biosynthesis and metabolism of cytokinins. Annu. Rev. Plant Physiol. 34:163-197.

Marousky, F.J. 1969. Vascular blockage, water absorption, stomatal opening, and respiration of cut 'Better times' roses treated with 8-hydroxyquinoline citrate and sucrose. J. Amer. Soc. Hort. Sci. 94:223-226.

Mayak, S., B. Bravdo, A. Gvilli, and A.H. Halevy. 1973. Improvement of opening of cut gladioli flowers by pretreatment with high sugar concentrations. Scientia Hort. 1:357-365.

Mayak, S. and D.R. Dilley. 1976. Effect of sucrose on response of cut carnations to kinetin, ethylene and abscisic acid. J. Amer. Soc. Hort. Sci. 101:583-585.

SAS Institute. 1989. SAS user's guide: Statistics. version 6 ed. SAS Inst., Cary, N.C. 